complete predictive value of suppression tests performed early during treatment. ${ }^{45}$

This study was supported by a grant to JSB from the Scottish Hospitals Endowments Research Trust. We thank Mrs Elizabeth McQueen for expert technical help.

${ }^{1}$ Ord, W M, and McKenzie, $\mathrm{H}$, in A System of Medicine, ed T C Allbutt, vol 4, p 489. London, McMillan, 1901.

2 White, W H, Quarterly fournal of Medicine, 1910, 4, 89.

3 Thomas, I D, Oddie, T H, and Myhill, J, fournal of Clinical Endocrinology and Metabolism, 1960, 20, 1601.

4 Alexander, W D, et al, Fournal of Clinical Endocrinology and Metabolism, 1970, 30, 540 .

${ }^{5}$ Lowry, R C, et al, British Medical fournal, 1971, 2, 19.

(Accepted 1 November 1978)

Departments of Therapeutics, Pathology, and Biochemical Medicine and the Division of Surgery, Ninewells Hospital and Medical School, Dundee, Scotland

T J WILKIN, MD, MRCP, lecturer in therapeutics (present address: Clinique des Maladies Métaboliques et Endocriniennes, Hôpital SaintEloi, 34059 Montpellier Cedex, France)

J SWANSON BECK, FRCP, FRCPATH, professor of pathology

J CROOKS, MD, FRCP, professor of therapeutics

$T$ E ISLES, PHD, BSC, senior lecturer in biochemical medicine

A GUNN, MD, FRCS, consultant surgeon

\section{Address card for obtaining accurate addresses of clinic patients}

In developing countries sufficient attention is not usually paid to recording complete and accurate addresses of clinic patients, since active follow-up is rare. A major problem also in routine tuberculosis treatment is the very high rate of drop-out, ${ }^{1}{ }^{2}$ much of it in the first three months. When a patient fails to attend a clinic on a due date in India it is the national policy to send a reminder postcard, a measure which can be successful only if the patient's address is recorded accurately. We report on the accuracy of addresses obtained with an "address card," a new approach.

\section{Methods and results}

In a tuberculosis clinic in Madras City we compared the accuracy of addresses of 355 patients obtained by (1) a registry clerk at the patient's first attendance; (2) a health visitor, with good knowledge of the area, at the second attendance-in about half the cases she knew whether a letter posted to the address recorded by the clerk had reached the patient; (3) an address card given to the patient at the second attendance to be completed by the postman or any literate neighbour, friend, or relative. This novel approach was employed because about half the patients were known to beilliterate. The address card was collected at the third clinic attendance, usually two or three days later. (If the address on it differed from that obtained by the health visitor earlier she carefully reinterrogated the patient.) The health visitor then visited the homes to verify the accuracy of the addresses obtained. When these were incorrect she tried to locate and record the correct address. The address that was finally confirmed by a home visit was used to assess the relative efficiencies of the three approaches.

Out of the 355 patients included in the study (table) the registry clerk recorded the correct address for only $66 \%$ and a nearly correct address for $10 \%$ more, an efficiency of $76 \%$. The health visitor improved the efficiency to $85 \%(\mathbf{P}<0.001)$. The address card was returned by $320(90 \%)$ patients.

Accuracy of home addresses of 355 patients obtained from three sources

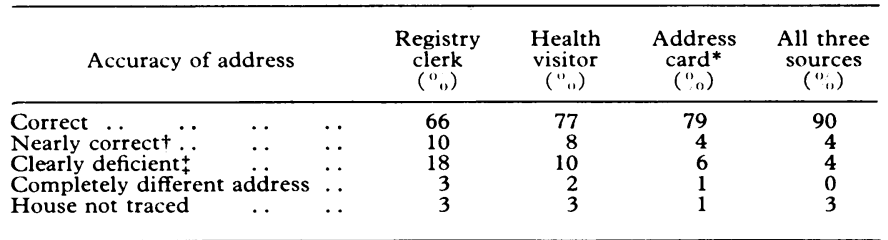

*Not brought back to clinic by $35\left(10^{\prime \prime}\right.$ ") patients.

$\ddagger$ Door number or street in door number or street name.
It had been completed most commonly by a neighbour ( $38 \%$ ), followed by a relative $(22 \%)$ or a friend $(20 \%)$, and then the postman $(13 \%)$. Its accuracy was over $90 \%$ regardless of who had recorded the address. It was slightly more efficient than the health visitor $(91 \%$ compared with $87 \%, P=0.04)$. Considering failure to return the address card as a clear deficiency also, its overall efficiency was $82 \%$, which is still appreciably better than the clerk's efficiency $(P=0.02)$. The efficiency achieved by the three sources together was only $94 \%$. Indeed, $10(3 \%)$ of the 355 houses were never traced.

In a second study in another tuberculosis clinic the registry clerk recorded the patient's address at the first attendance and a letter was posted the same afternoon. On the same day a health visitor gave the patient an address card. When this card was returned ( $6 \%$ were not returned) a letter was posted to the address recorded on it. Information on receipt was available for both the letters in 68 patients. The letter using the address on the card was received by $94 \%$ of the patients compared with $84 \%$ using the address recorded by the clerk $(P=0.05)$

\section{Comment}

The address card has proved to be an inexpensive, convenient, acceptable, and novel method for obtaining accurate addresses. It is worthy of further investigation under widely different conditions. In a few instances literate patients objected to asking another individual to complete the card, but this was exceptional. Although our observations are based on tuberculous patients or suspects they are relevant to all follow-up studies, especially of patients with chronic diseases requiring long periods of treatment.

${ }^{1}$ Parthasarathy, R, and Frimodt-Moller, J, Proceedings of the 19th TB and Chest Diseases Workers Conference, Delhi. 1964, $\mathrm{p} 31$.

${ }^{2}$ Fox, W, Bulletin of the International Union Against TB, 1972, 47, 49.

(Accepted 1 November 1978)

Government Chest Institute, Madras-31, India

K V KRISHNASWAMI, MD, FCCP, director

ICMR Tuberculosis Research Centre, Madras-31, India

M C SATAGOPAN, MSC, statistical assistant

P R SOMASUNDARAM, BA, DIPSTAT, statistician

$S$ P TRIPATHY, MD, director

ICMR Institute for Research in Medical Statistics, Madras-31, India S RADHAKRISHNA, PHD, deputy director

MRC Tuberculosis and Chest Diseases Unit, London SW3 6HP

WALLACE FOX, FRCP, FFCM, director

\section{Osteomyelitis due to Streptococcus equisimilis (group C)}

Streptococcus equisimilis is rarely isolated from blood cultures. We describe a patient with cervical osteomyelitis who presented with chest pain and fever and who had a septicaemia due to this organism.

\section{Case report}

A 65-year-old retired clerk presented with a three-day history of malaise, vomiting, headache, and fever. $\mathrm{He}$ was feverish $\left(40^{\circ} \mathrm{C}\right)$ and notably tender over the muscles of the chest wall. The blood count was normal (white cells $\left.9 \cdot 2 \times 10^{9} / 1\left(9200 / \mathrm{mm}^{3}\right)\right)$; the initial ESR was $55 \mathrm{~mm}$ in the first hour (Westergren), rising to $85 \mathrm{~mm}$ one week later; and the mid-stream urine was normal. The brucella complement fixation test was negative as was a full viral screen. Cultures of blood taken on the day of admission and two days later grew a beta-haemolytic streptococcus of Lancefield group C. The organism was identified as Streptococcus equisimilis. The strain was fully sensitive to benzyl penicillin. Treatment was started with amoxycillin and cloxacillin (before the results of the blood cultures) and continued for two weeks. His temperature settled and his general condition improved rapidly. No source of the infection was found.

A month later he was readmitted with a prominent tender kyphus at the junction of the 6 th and 7 th cervical vertebrae (C6/7). There were no other symptoms and the only physical signs were bilateral absence of the triceps tendon reflexes. The ESR was $42 \mathrm{~mm}$ in the first hour. $X$-ray examination showed destruction of the body of $\mathrm{C} 6$, the $\mathrm{C} 6 / 7$ disc space, and the superior body of $\mathrm{C} 7$ with partial collapse of $\mathrm{C} 6$ and a soft tissue swelling. These appearances were suggestive of osteomyelitis. Six blood cultures taken over 10 days were sterile. Chest $x$-ray picture showed no evidence of tumour or 


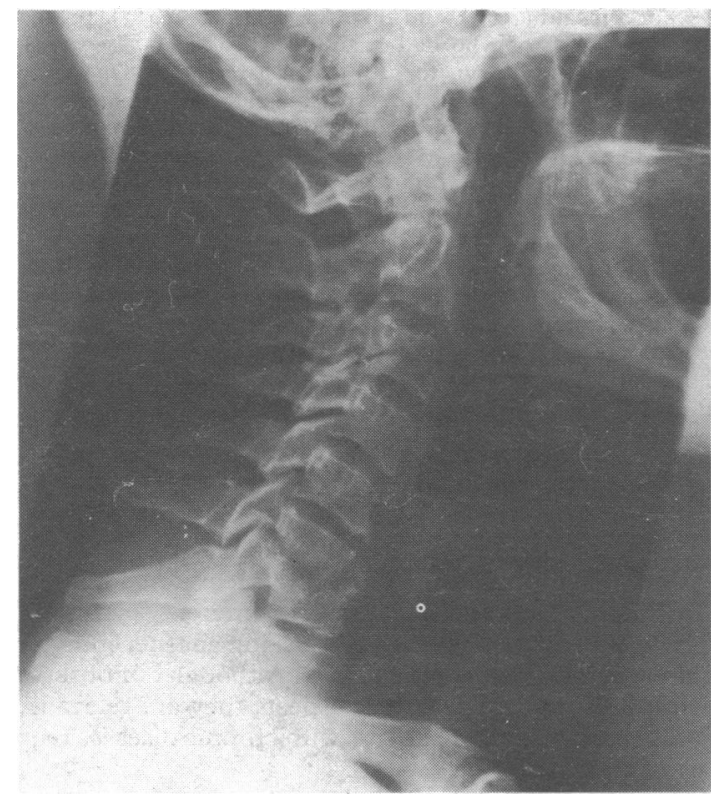

Osteomyelitis affecting 6 th and 7 th cervical vertebrae.

tuberculosis. Early morning urine specimens showed no evidence of tuberculous infection and the Mantoux was positive only at 1 in 1000 . He was treated with cloxacillin $1 \mathrm{~g}$ and benzyl penicillin $2 \mathrm{MU}$ six-hourly intravenously for one week, then $1 \mathrm{~g}$ and $1 \mathrm{MU}$ respectively intramuscularly for one week, followed by six weeks of penicillin V $500 \mathrm{mg}$ and cloxacillin $500 \mathrm{mg}$ six hourly by mouth. Throughout this time probenecid $500 \mathrm{mg}$ six hourly was given. His neck was immobilised in a stiff collar. Over the next five months the bodies of $\mathrm{C} 6 / 7$ fused completely. He has remained well throughout the subsequent 10 months.

Samples of serum taken at the time of the two admissions were examined for streptococcal antibodies. The antistreptolysin $O$ titre rose from 86 to 310 Todd units (normal $<200$ ) and the anti-M associated protein titre rose from 10 to $90-160$ (normal $<10$ ). The antistaphylolysin titre was $<2$ units (normal).

\section{Comment}

The interesting features of this case are the unusual infecting organism and the presentation with chest tenderness, which in retrospect, possibly represented early cervical spine disease. Nevertheless, the chest tenderness settled very rapidly, and it was one month before the cervical osteomyelitis was recognised. Group C streptococci are found in the throats of $2-3 \%$ of healthy adults in Europe and North America. They are generally of the biotype $S$ equisimilis. $S$ equisimilis causes pharyngitis and skin infection and, formerly, puerperal sepsis. ${ }^{12}$ In the series of patients with systemic disease due to streptococci reported by Parker and $\mathrm{Ball}^{3}$ group C streptococci were the least common of the easily identifiable streptococci. $S$ equisimilis is a cause of septicaemia and arthritis in 1 to 3 -week-old pigs ${ }^{4}$ and septic arthritis has occasionally been reported in man. ${ }^{5}$ Our patient had had no contact with animals. We have found no reports of osteomyelitis due to this organism.

We thank the Cross Infection Reference Laboratory, Colindale, for identifying the organism and for performing the streptococcal serology, Dr T D R Hockaday for permission to report the case, Dr J B Latham for reviewing the radiographs, and Dr $R$ T Mayon-White for information on group $\mathrm{C}$ streptococcal infections reported to the Communicable Disease Surveillance Centre.

1 Hutchinson, R I, British Medical fournal; 1946, 2, 575.

2 Duma, R J, et al, Medicine, Baltimore, 1969, 48, 87.

3 Parker, M T, and Ball, L C, Fournal of Medical Microbiology, 1976, 9, 275.

4 Collier, J R, Proceedings of the American Veterinary Medical Association, 1951, 88, 169.

${ }^{5}$ Mayon-White, R T, 1978, personal communication.

(Accepted 1 November 1978)

Radcliffe Infirmary, Oxford OX2 6HE

C M ASPLIN, MRCP, senior registrar

N J BEECHING, MA, BM, house physician

MARY P E SLACK, MA, MB, lecturer in bacteriology

\section{Electroconvulsive therapy for patient with cardiac pacemaker}

There have been few reports of electroconvulsive therapy (ECT) for patients with cardiac pacemakers and none in Britain. The effect of the ECT current on the pacemaker and the possibility of cardiac arrhythmias generate concern about the use of this treatment in depressed patients with pacemakers. We report a case in which treatment was successful.

\section{Case report}

A 71-year-old man with a four-year history of recurrent agitated depression was admitted to hospital because he had ceased to respond to adequate doses of amitriptyline. He had physiological features of depression, was agitated and depressed, preoccupied with ideas of unworthiness, self-reproach, remorse, and guilt. His premorbid personality was suggestive of a conscientious, meticulous, and obsessional person. He had had a permanent demand pacemaker (model ELA staniun unit 570 NSM) implanted in April 1977, a month before his admission, for complete heart block diagnosed in 1973. In view of the severity and unresponsiveness of his depression he was treated with a course of five bilateral electroconvulsions, two a week (Ectron model 220V DC $\times 1.0 \mathrm{sec}(\mathrm{c})$ ), and his cardiac function was monitored throughout the treatment (Hewlitt, Packard $1511 \mathrm{~B}$ ). His pulse rate was constant at $70 / \mathrm{min}$. ECG tracings before and immediately after the ECT showed no change in rate or rhythm (figure 1). In comparison a patient of the same age without a pacemaker who had ECT showed typical post-ECT bradycardia. Atropine was not given as premedication because the pacemaker itself eliminated the chances of bradyarrhythmias. He responded well to five treatments, losing all his symptoms. Six months later he was readmitted with a recurrence of his original depressive symptoms. He was once again successfully treated with a course of eight electroconvulsions and imipramine. Monitoring during treatment showed no abnormality.

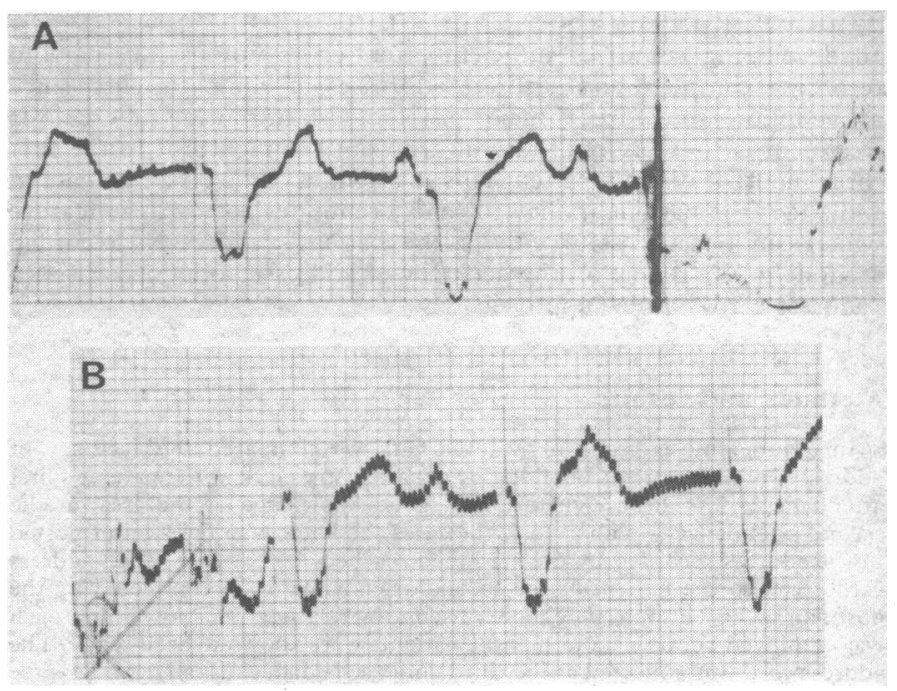

Electrocardiogram of patient with pacemaker (A) before ECT, (B) immediately after ECT.

\section{Comment}

The two main hazards of ECT in patients with pacemakers, the possibility of arrhythmias and the ECT current affecting the pacemaker, have been studied by Youmans and his colleagues ${ }^{1}$ using dogs with implanted electrodes. They found that dogs with pacemakers had one-third the arrhythmias of controls. Moreover, all the arrhythmias occurred in dogs with transvenous electrodes. In other reported cases ${ }^{2}{ }^{3}$ there was no evidence of ECT-induced arrhythmias. On the other hand, the pacemaker provides a form of "built-in" protection against the serious bradyarrhythmias, which account for $30 \%$ of all cardiac arrhythmias seen during ECT. ${ }^{1-3}$

One of the main indications for atropine premedication in ECT is to prevent bradycardia. 4 Since the pacemaker eliminates this complication premedication with atropine is best avoided. Implanted

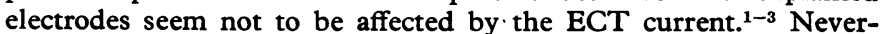
theless, proper grounding to ensure that no current passes over the implanted low-resistance pathway to the myocardium is essential. There should be no contact between the patient and the ground 